\title{
RETINOBLASTOMA: A THREE-YEAR-STUDY AT A BRAZILIAN MEDICAL SCHOOL HOSPITAL
}

\author{
Maria Teresa Brizzi Chizzotti Bonanomi, ${ }^{\mathrm{I}}$ Maria Tereza Assis de Almeida, ${ }^{\mathrm{II}}$ \\ Lilian Maria Cristofani," Vicente Odone Filho ${ }^{\text {II }}$
}

doi: $10.1590 / \mathrm{S} 1807-59322009000500010$

Bonanomi MTBC, de Almeida MTA, Cristofani LM, Odone Filho V. Retinoblastoma: a three-year-study at a Brazilian medical school hospital. Clinics. 2009;64(5):427-34.

OBJECTIVE: To present the characteristics and treatment outcomes of patients with retinoblastoma.

METHODS: A retrospective case series was conducted to review the records of all new patients diagnosed with retinoblastoma between 2003 and 2005. Eyes with early disease, or advanced disease with potential vision were treated with chemotherapy (carboplatin and etoposide) in conjunction with early local therapy (laser or cryo). Radiotherapy was used in cases where the disease did not respond to the above protocols or in recurrent cases. Eyes in the late stage of disease with no potential vision in the initial examination or eyes and where conservative treatment had failed were enucleated.

RESULTS: In total, we reviewed 28 new cases of retinoblastoma, 15 of which were unilateral and 13 of which were bilateral $(46 \%)$. These data correspond to a mean of 9.3 new cases per year $(0.77$ case/ month). The mean age at diagnosis was 33.8 months for unilateral cases, and 19.15 months for bilateral cases $(\mathrm{p}=0.015)$. Leucocoria was the major presenting symptom $(75 \%)$. All but one patient with unilateral disease had the affected eye enucleated due to advanced disease (mean follow-up: 39.91 months). Among the 13 bilateral cases, 13 eyes (50\%) were enucleated, 11 eyes (42.4\%) were saved with chemotherapy in conjunction with local therapy and 2 eyes (7.6\%) were saved using external beam radiotherapy (mean follow-up: 41.91 months). In unilateral and bilateral disease, pathology data revealed choroid involvement in 50\% and 30\%, respectively, and optic nerve invasion in $92 \%$ and $50 \%$, respectively.

CONCLUSION: In this population, retinoblastoma was diagnosed too late and most eyes were consequently enucleated. In cases with bilateral disease, half of the eyes were preserved.

KEYWORDS: Retinal neoplasm; Retinoblastoma; Chemotherapy/adjuvant; cryotherapy; Laser therapy.

\section{INTRODUCTION}

Retinoblastoma is a highly problematic malignancy during childhood due to its potential threat to both sight and life. This highly malignant neoplasm is known to originate from the nuclear layers of the retina following two genetic hits that suppress both alleles of the $r b 1$ gene. ${ }^{1}$ While enucleation of the affected eye is curative for intraocular

I Divisão de Clínica Oftalmológica, Hospital das Clínicas da Faculdade de Medicina da Universidade de São Paulo - São Paulo/SP, Brazil.

II Treatment of Children with Cancer Institute (ITACI), Instituto da Criança do Hospital das Clínicas da Faculdade de Medicina da Universidade de São Paulo - São Paulo/SP, Brazil.

Email: mtbonanomi@uol.com.br

Tel.: 55113069.7873

Received for publication on December 21, 2008

Accepted for publication on March 02, 2009 tumors, the therapeutic approach for retinoblastoma treatment has undergone changes in recent years in an attempt to preserve the eye, and thus maintain some degree of vision. Presently, the control of small tumors may be achieved through focal therapy, transpupillary thermotherapy (TTT) ${ }^{2-5}$ photocoagulation, ${ }^{6}$ cryotherapy ${ }^{7-8}$ and radioactive plaque techniques. ${ }^{9}$ Retinoblastoma is highly vulnerable to external beam radiation (EBRT) which, for many years, served as the only conservative treatment available for large tumors. ${ }^{10}$ Despite a high rate of preserved eyes, ${ }^{11}$ EBRT has been associated with facial bone hypoplasia, with aesthetic consequences and, more importantly, with an increased risk of a second malignancy in patients with a germinal mutation. ${ }^{12,13}$ Notwithstanding the development of new radiation techniques such as Intensity Modulated Radiation Therapy, ${ }^{14}$ efforts have been made to postpone radiotherapy 
until the child is at least one year of age, in order to minimize potential sequelae. ${ }^{12}$ Over the last decade, several groups have used chemotherapy as a useful tool to achieve this goal. The systemic use of two or three drugs may lead to an impressive shrinking of large tumors, but in most cases this method alone is not effective. ${ }^{4,15-17}$ Focal consolidation, as introduced by Murphree and others, ${ }^{2,14}$ is necessary to truly kill the tumor in as many as $90 \%$ of the cases. The present study was conducted to assess the epidemiology and results of the current therapeutic methods in our patients. This paper presents data on the outcomes of new retinoblastoma cases treated between 2003 and 2005 at the Hospital das Clínicas da Faculdade de Medicina da Universidade de São Paulo (HC-FMUSP) in cooperation with the Institute for the Treatment of Children with Cancer (ITACI).

\section{METHODS}

This is a retrospective case series approved by the ethics committee at our facility. Every patient with a suspected retinoblastoma was managed as an ophthalmology inpatient and underwent both local and systemic workups. We evaluated all records of newly diagnosed cases of retinoblastoma between January of 2003 and December of 2005. The ophthalmologic examination, under sedation or general anesthesia, including indirect ophthalmoscopy and USG, Magnetic Resonance Imaging (MRI) and radiotherapy were all performed at the Hospital das Clínicas da Faculdade de Medicina da Universidade de São Paulo (HC-FMUSP).

The systemic workup: A physical exam, renal and liver function tests and the administration of chemotherapy were conducted at the ITACI. Each patient described in this report was treated according to a predefined protocol, and the same physician treated all of the patients in the study at both institutions. Cerebrospinal fluid samples were obtained only when the MRI suggested a suspicious extra-ocular tumor.

Tumors were characterized using two classification systems: Reese Ellsworth (RE) ${ }^{18}$ and Murphree's (ABC). ${ }^{19}$ When assessing an eye's eligibility for treatment, tumors were initially evaluated in terms of the need for volume reduction or the possibility of management using local therapy alone. Patients with tumors requiring shrinkage, RE groups I to $\mathrm{V}$ or $\mathrm{ABC}$ classifications $\mathrm{B}$ to $\mathrm{D}$ (in groups $\mathrm{V}$ or $\mathrm{D}$ the potential for vision was considered when planning for conservative treatment), were treated with four to nine cycles of systemic chemotherapy with etoposide (VP-16) 100mg/ $\mathrm{m}^{2} /$ day on the first and second days and carboplatin 540mg/ $\mathrm{m}^{2} /$ day on the first day only. This schedule was repeated after three to five weeks (ideally after four weeks), based on the clinical status of the child. When the chemotherapeutic program promoted shrinkage of the tumor to a maximum height of $4 \mathrm{~mm}$, focal consolidation using an $810 \mathrm{~nm}$ diode laser or cryotherapy was added. The child was initially placed under general anesthesia; the eyes were examined with indirect ophthalmoscopy and scleral depression. The tumors were then treated and, immediately after the child received chemotherapy. The number of cycles of chemotherapy or focal consolidation was determined clinically by the same ophthalmologist (MTBCB) based on the fundus findings. We enucleated all eyes classified as stage $\mathrm{E}$ under the $\mathrm{ABC}$ classification, i.e., involving secondary eye disease due to the advanced status of the tumor. If we identified orbital inflammation or suspected extra ocular disease, two cycles of the same chemotherapeutic regime were administered prior to the enucleation procedure. Otherwise, all eyes in $\mathrm{ABC}$ stage A, or in RE group I with very small tumors (3 mm diameter or less) received only local laser or cryo treatment. In some cases cryotherapy was also used to enhance intra eye drug penetration. ${ }^{8}$

After treatment, bimonthly follow-up visits were conducted to examine for residual or new tumors, recurrence, and vitreous or subretinal seed reactivation. In positive cases, the patient was scheduled for radiotherapy or enucleation. In the rare cases where plaque radiotherapy was indicated, the child was referred to another service. Follow-up was considered complete when the eyes were free from viable tumors for a minimum of eight months, when the child was free from extra-ocular tumors in the case of bilateral enucleation, or in the case of death.

Laser therapy was delivered by modified transpupillary thermotherapy (TTT) ${ }^{14} \mathrm{~A}$ continuous pulse diode laser (810nm - OPTO, São Carlos, Brazil) was delivered through the dilated pupil with a spot size of $3 \mathrm{~mm}$ and a 20 diopter lens. The power was set at $350 \mathrm{~mW}$ and the spot was held in place for the time required to produce a visible grayishwhite appearance of the tumor. For this to occur properly, the spots had to overlap to ensure that the entire surface of the tumor would be covered. A conscious effort was made not to increase the power, in order to prevent hemorrhages on the tumor surface. On selected tumors, the classic photocoagulation pattern was applied. ${ }^{6}$

EBRT was applied under general anesthesia in daily doses of 2 Gy over five weeks, excluding the weekends, for a total of $45 \mathrm{~Gy}$. All tumors were followed under sedation or general anesthesia with indirect ophthalmoscopy and B-scan ultrasound.

Enucleated eyes were fixed in formaldehyde and studied both macroscopically and under optical microscopy. The pathological examination of the enucleated eyes was conducted with special care to identify the optic nerve and choroid invasion. In addition, the Chantada classification was used for the enucleated eyes. ${ }^{20,21}$ 
In terms of quantitative variables, the analysis included observed minimum and maximum values, calculated mean, standard deviation and median. For the qualitative variables, the absolute and relative frequencies were calculated. The non-parametric Mann-Whitney test was used to compare the two groups. To assess homogeneity, the chi-square test or the Fisher's exact test were used, at the significance threshold level of $5 \%$.

\section{RESULTS}

Of the 38 patients whose records we assessed, eight were diagnosed before the study period and two suffered from diseases other than retinoblastoma: one patient had Coat's disease and one had capillary hemangioma. Between 2003 and 2005 there were 28 new cases of retinoblastoma representing a mean of 9.3 cases per year, or 0.77 new cases each month. The 28 patients included 15 (53.6\%) with unilateral and $13(46.4 \%)$ with bilateral tumors. A positive family history of retinoblastoma was present in two cases (7\%) - one unilateral and one bilateral retinoblastoma. Detailed patient characteristics are listed in Table 1. There were no gender differences across any of the groups.
Throughout the entire patient cohort, leucocoria was the presenting symptom in 21 cases $(75 \%)$; orbital inflammation, glaucoma and proptosis were present in four cases $(14 \%)$ and strabismus in three cases $(11 \%)$ patients. The time and follow-up profile of the cases is shown in Table 2, where we observed a statistically different age at diagnosis, a mean of 35 months for unilateral and of 18 months for bilateral cases $(\mathrm{p}=0.015)$.

Of the 15 unilateral cases, $12(80 \%)$ presented with leucocoria, one $(6.7 \%)$, with proptosis and two $(13.3 \%)$ with orbital inflammation. All patients exhibited advanced intraocular disease at presentation (one eye with no classification record) as shown in Table 3. Of these 15 eyes, none had a potential for vision and 14 (93.3\%) were enucleated (Table 4); in one patient, tumoral involvement of the CNS precluded surgery. This patient was treated with chemotherapy and eventually died after uncontrollable CNS tumor. The other patient who submitted to chemotherapy in this group survived despite tumoral invasion of the surgical margins of the optic nerve.

Of the 13 bilateral cases, nine $(69.2 \%)$ presented with leucocoria, three $(23.1 \%)$ with strabismus, and one $(7.7 \%)$ with secondary glaucoma and buphthalmus. In this group, all

Table 1 - Patients characteristics. There is no variation in prevalence related to gender

\begin{tabular}{|c|c|c|c|c|c|c|}
\hline & & \multicolumn{4}{|c|}{ Group } & \\
\hline & & \multicolumn{2}{|c|}{ unilateral } & \multicolumn{2}{|c|}{ bilateral } & \\
\hline \multirow[t]{2}{*}{ total of patients (eyes) } & & $\mathrm{n}$ & $\%$ & $\mathrm{n}$ & $\%$ & $\mathrm{p}$ \\
\hline & & $15(15)$ & 53.6 & $13(26)$ & 46.4 & \\
\hline \multirow[t]{2}{*}{ gender } & female & 7 & 46.6 & 6 & 46.1 & $0.978 *$ \\
\hline & male & 8 & 53.3 & 7 & 53.8 & \\
\hline
\end{tabular}

*: qui-square test.

Table 2 - Presentation characteristics and follow-up. The lag time is the time elapsed between the first symptom and the diagnosis. There is a significant difference in the age of the child when the diagnosis was made between the unilateral and bilateral groups

\begin{tabular}{|c|c|c|c|c|c|c|c|c|}
\hline & group & $\mathrm{n}$ & mean & PD & $\min$ & $\max$ & median & $\mathrm{p}$ \\
\hline \multirow[t]{2}{*}{ age at diagnosis (months) } & unilateral & 15 & 33.8 & 15.68 & 9 & 65 & 35.00 & 0.015 \\
\hline & bilateral & 13 & 19.15 & 10.75 & 2 & 36 & 18.00 & \\
\hline \multirow[t]{2}{*}{ lag time (months) } & unilateral & 14 & 8.29 & 7.05 & 1 & 24 & 9.00 & 0.437 \\
\hline & bilateral & 10 & 5.60 & 5.42 & 1 & 18 & 4.50 & \\
\hline \multirow[t]{2}{*}{ total follow-up (months) } & unilateral & 11 & 39.91 & 7.44 & 28 & 54 & 35.00 & 0.193 \\
\hline & bilateral & 9 & 41.91 & 10.09 & 23 & 58 & 43.00 & \\
\hline CNS Retinoblastoma & unilateral & $1(“)$ & 6.6 & & 0 & & & \\
\hline metastatic disease & & 0 & & & 0 & & & \\
\hline death & unilateral & $1(“)$ & & & 0 & & & \\
\hline
\end{tabular}

n: number; PD: pattern deviation; min: minimum; max: maximum; (“): Central Nervous System (CNS) invasion at presentation; p:Mann Whitney test 
Table 3 - Reese-Ellsworth (RE) and Murphree ABC classification for all patients. Between the horizontal bars the eyes are grouped using the RE classification (first interval), in less advanced retinoblastoma (RE: Ia to IVb) and more advanced tumor (RE: $\mathrm{Va}$ and $\mathrm{Vb}$ ), and using the $\mathrm{ABC}$ classification (second interval), in less advanced retinoblastoma (A,B,and C) and more advanced tumor (D and E). There is a difference between the two groups when the number of eyes is considered

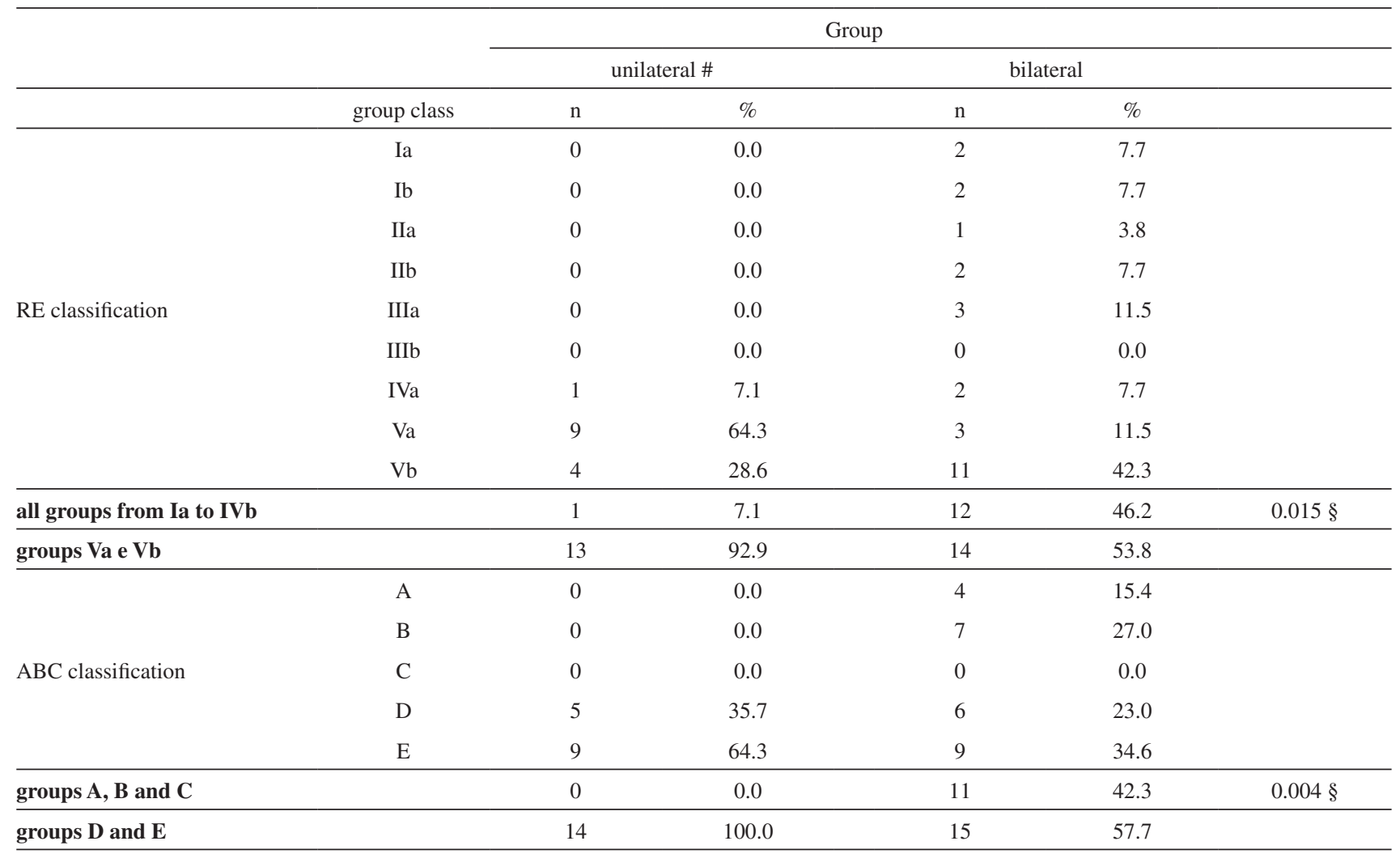

$\S$ : Fisher exact test; \#: one case without classification record.

Table 4 - Enucleation and conservation rate in unilateral and bilateral retinoblastoma. All eyes in the unilateral group were enucleated. Half of the eyes were preserved in the bilateral group, including $42 \%$ without the need of EBRT

\begin{tabular}{|c|c|c|c|c|c|}
\hline & \multicolumn{4}{|c|}{ Group } & \\
\hline & \multicolumn{2}{|c|}{ unilateral } & \multicolumn{2}{|c|}{ bilateral } & \\
\hline & $\mathrm{n}$ & $\%$ & $\mathrm{n}$ & $\%$ & \\
\hline enucleation & 14 & $93.3 * *$ & 13 & 50 & $0.005 *$ \\
\hline eye conserved without EBRT & 0 & 0 & 11 & 42.4 & $0.003 \S$ \\
\hline eye conserved with EBRT & 0 & 0 & 2 & 7.6 & $0.524 \S$ \\
\hline
\end{tabular}

* qui-square test; §: Fisher exact test; EBRT: external beam radiotherapy; n: number of eyes; ** One patient was not enucleated (CNS complication at presentation).

eyes had their classifications recorded (Table 3). The table shows that while all unilateral cases had advanced disease, nearly $50 \%$ of the eyes in bilateral cases were classified as less advanced retinoblastoma (46.2\% under the RE and $42.3 \%$ under the ABC classification). This is a significant difference when comparing less advanced (RE: Ia to IVb, $\mathrm{ABC}$ : $\mathrm{A}$ to $\mathrm{C}$ ) versus more advanced (RE: $\mathrm{Va}$ and $\mathrm{Vb}, \mathrm{ABC}$ : $\mathrm{D}$ and $\mathrm{E}$ ) stages between the unilateral and bilateral groups ( $p=0.015, p=0.004)$. Of the 13 patients, 12 underwent the chemotherapeutic protocol for tumor reduction. One patient was treated with primary enucleation of one eye (group $\mathrm{Vb} / \mathrm{E}$ ) and with laser and cryo on the other eye (group IIIa/A). The number of eyes that were preserved is listed in Table 4. The enucleation rates were $93.3 \%$ (15 eyes) for unilateral retinoblastoma and 50\% (13 eyes) for bilateral retinoblastoma, including two children who underwent bilateral surgery $(\mathrm{p}=0.005)$. Eye conservation without EBRT also showed a significant difference between the two groups, the recorded totals being zero and eleven (42.4\%), respectively $(\mathrm{p}=0.003)$. 
Table 5 - Anatomopathologic characteristics. Not all features were described in each anatomic piece so, the "n" is variable

\begin{tabular}{|c|c|c|c|c|c|c|}
\hline \multirow[t]{2}{*}{ feature } & & \multicolumn{2}{|c|}{ unilateral } & \multicolumn{2}{|c|}{ bilateral } & \multirow[b]{2}{*}{$\mathrm{p} \S$} \\
\hline & & $\mathrm{n}$ & $\%$ & $\mathrm{n}$ & $\%$ & \\
\hline \multirow[t]{2}{*}{ FW rosette } & no & $5(8)$ & 62.5 & $5(5)$ & 100.0 & \\
\hline & yes & $3(8)$ & 37.5 & $0(5)$ & 0.0 & 0.231 \\
\hline \multirow[t]{2}{*}{ HW rosette } & no & $2(8)$ & 25.0 & $2(5)$ & 40,0 & \\
\hline & yes & $6(8)$ & 75.0 & $3(5)$ & 60.0 & 1.0 \\
\hline \multirow[t]{2}{*}{ choriocappilaris } & no & $3(11)$ & 27.27 & $4(10)$ & 40.0 & \\
\hline & yes & $8(11)$ & 72.72 & $6(10)$ & 60.0 & 0.659 \\
\hline \multirow[t]{2}{*}{ choroids } & no & $6(12)$ & 50.0 & $7(10)$ & 70.0 & \\
\hline & yes & $6(12)$ & 50.0 & $3(10)$ & 30.0 & 0.415 \\
\hline \multirow[t]{2}{*}{ nerve invasion } & no & $1(12)$ & 8.3 & $5(10)$ & 50.0 & \\
\hline & yes & $11(12)$ & 91.6 & $5(10)$ & 50.0 & 0.056 \\
\hline \multirow[t]{2}{*}{ level } & postlaminar & $5(11)$ & 45.4 & $1(5)$ & 20.0 & \\
\hline & prelaminar & $6(11)$ & 54.6 & $4(5)$ & 80.0 & 0.808 \\
\hline \multirow[t]{2}{*}{ Chantada } & I & $11(12)$ & 91.6 & $10(10)$ & 100.0 & \\
\hline & II & $1(12)$ & 8.3 & $0(10)$ & 0.0 & 1.0 \\
\hline \multirow[t]{3}{*}{ rubeosis and GS } & no & $4(12)$ & 33.3 & $2(10)$ & 20.0 & \\
\hline & yes plus GS & $3(12)$ & 25.0 & $7(10)$ & 70.0 & 0.158 \\
\hline & yes without GS & $5(12)$ & 41.6 & $1(10)$ & 10.0 & \\
\hline
\end{tabular}

PD: patern deviation; FW: Fexner-Wintersteiner, HW: Homer-Wright, SM: surgical margin, GS: goniossinechia, § Fisher exact test: not significant for all studied parameters. ( ) total of eyes with feature description; prelaminar: neve invasion anterior to the lamina cribrosa; poslaminar: nerve invasion posterior to the lamina cribrosa

The pathology findings are displayed in Table 5. The data illustrates that despite the absence of significant differences between the unilateral and bilateral groups, nerve invasion had borderline significance, occurring in $91.7 \%$ and $50 \%$ of cases, respectively (Table $5 ; \mathrm{p}=0.056$ ). The Chantada classification was I in eleven eyes, and II in one eye for unilateral tumors. All enucleated eyes in bilateral retinoblastoma cases had a Chantada classification of I.

\section{DISCUSSION}

This study is part of a general design of surveys carried out at HC-FMUSP. ${ }^{22}$ The reported incidence of retinoblastoma in countries around the globe varies from 1 in 15,000 to 1 in 20,000 live births. ${ }^{14}$ Existing data for the United States have recently been reviewed and suggests that retinoblastoma may represent $6.1 \%$ of all childhood cancers, implying an age-adjusted incidence of 11.8 per million (children 0-4 years). In one study, the authors state that the proportion of bilateral cases (26.6\%) versus unilateral cases (71.9\%) has remained stable over the past 30 years. ${ }^{23}$ This is much less than the $50 \%$ bilateral disease rate identified in our study and in previous Brazilian reports. ${ }^{5,21}$ Although there is a potential correlation between environmental variables such as food intake and viral infection with the occurrence of retinoblastoma, environmental factors are not expected to influence the incidence of bilateral tumors (germ mutation) ${ }^{25-27}$ Consequently, one possible explanation for our high rate of bilateral disease could be the enucleation approach to unilateral retinoblastoma elsewhere in the country before the child can be referred to a specialized oncology center such as our institution. A positive family history was present in two (7\%) of our patients, which is in agreement with the average figure of 7 to $10 \%$ described in the literature. ${ }^{14}$ The average time elapsed between the first symptom and diagnosis, i.e., the lag time, was 8.29 months (range 1 to 24) for unilateral and 5.6 months (range 1 to 18) for bilateral disease. As expected, there were no differences in relation to gender or laterality. The age at presentation was 33.8 months (range 9 to 65) for unilateral and 19.15 months (range 2 to 36 ) for bilateral retinoblastoma, which was shown to be significantly different $(\mathrm{p}=0.015)$, as also reported in the literature..$^{28}$ Leucocoria, considered a marker of advanced disease, is the leading presenting symptom in all publications and has been reported in $56 \%$ of the cases in a series of 1256 patients in the United States. ${ }^{28}$ Among our patients, it was the presenting symptom in 21 (71.4\%) patients, $80 \%$ in the unilateral and $69 \%$ in the bilateral group. Orbital inflammation, glaucoma and proptosis, which seldom occur in the United States population, were present in $14 \%$ of 
our patients, thus suggesting late diagnosis in Brazil. Small tumors in the fovea can reduce the visual acuity and cause strabismus, reported as the presenting symptom in $23.6 \%$ of cases.$^{28}$ Strabismus is a disfiguring sign that is easily noticed by a patient's family. For this reason, somewhat fortunately, this allows for an earlier diagnosis of a smaller and more treatable tumor. Strabismus occurred in $10 \%$ of our patients, and was only seen in the bilateral group.

The Reese Ellsworth group classification (RE),${ }^{18}$ used in most publications, was designed to predict the prognosis of retinoblastoma and ocular salvage following treatment with EBRT. Under this classification, the smallest tumor size considered is four disc diameters, which is approximately $6 \mathrm{~mm}$. A tumor of this size cannot be managed with focal treatment alone, while tumors that are $3 \mathrm{~mm}$ or less in diameter may be treated with cryo $^{7}$ or laser techniques alone. ${ }^{6,14}$ This evidence is linked with the observation that tumors less than $3 \mathrm{~mm}$ in size have a better prognosis, ${ }^{29}$ rendering Murphree's ABC classification ${ }^{19}$ more appropriate. However, since this last classification is still under review, ${ }^{14,30}$ we used both systems to classify all of our patients.

All patients with unilateral tumors had advanced disease, diagnosed at stages D or E (Table 3). Diseases caused by the tumor in these cases were classified as intraocular dissemination, under the retina, or in the vitreous and its complications (RE classification correspondence: IVa: 1 eye, Va: 9 eyes and $\mathrm{Vb}$ : 4 eyes, including 1 eye with no classification record). In our oncology service, eyes in group $\mathrm{D}$ with unilateral disease and no potential vision were not eligible for conservative treatment. Consequently, all patients but one had the affected eye enucleated. Late diagnosis was also a characteristic of bilateral tumors. In this group, 15 eyes from 11 patients were classified under groups D or E (Table 3), including two boys who were already blind at the first visit and required bilateral enucleation for uncontrollable intraocular disease by the end of the two-year treatment, despite additional radiotherapy. Of these 15 eyes, only two could be preserved, both with the use of EBRT.

External beam radiotherapy was the only alternative to enucleation until the mid 1990s and is still an option to treat large tumors. ${ }^{13}$ This type of treatment, excluding the disfigurement due to bone hypoplasia, predisposes children with germ mutation to secondary malignancies. This is especially true when the patient treated is under the age of 12 months. ${ }^{16}$ Chemotherapy is useful to shrink the tumor and make it suitable for local treatment, and also has the effect of postponing the need for EBRT, ${ }^{2-5,15-17,30-32}$ although in most cases it is not effective alone. In a randomized prospective study in which 457 tumors were treated with the three drugs etoposide, carboplatin and vincristine, alone or in combination with local treatment involving cryotherapy and thermotherapy, Shields et $\mathrm{al}^{16}$ demonstrated, using Kaplan-Meier analysis, a recurrence of $45 \%$ with chemotherapy alone and $18 \%$ with the combined treatment. Wilson et al, ${ }^{31}$ assuming that etoposide was not necessary to treat retinoblastoma, studied 16 patients (11 bilateral and 5 unilateral). In this study, $74.1 \%$ of cases were in group V. Using only two drugs, vincristine and carboplatin, and using early focal treatment the researchers were able to achieve an ocular survival rate of $81 \%$, with 5 eyes $(30 \%)$ receiving EBRT. In our study, using two different drugs, carboplatin and etoposide, only $50 \%$ of the eyes were salvaged in cases of bilateral disease, including two eyes $(7.6 \%)$ that needed EBRT for tumor control (Table 4). Of the 13 bilateral patients, only one child was not treated with chemotherapy. This child was classified as group Ia/A in one eye, which received only local treatment, and group Va/D with no potential vision in the other eye, which was enucleated.

A study conducted in the Turkish population reported the causes of failure during a three-drug regime plus local treatment, and evaluated the need for ERBT. In 105 eyes from 71 children, older age, greater tumor thickness, presence of vitreous seeds and subretinal fluid at baseline, together with retinal tumor recurrence after chemo reduction, were all shown to be associated with the need for enucleation. ${ }^{32}$ The authors of this study reported globe salvage of $69.5 \%$, including $23.2 \%$ that needed EBRT across all RE groups.

Groups D and E are the true challenge for oncologists and ophthalmologists. In our patients, all eyes in groups A to $\mathrm{C}$ were preserved while only two of the 15 eyes at more advanced stages were not enucleated. These data are even more disheartening if we pool together the eyes with advanced disease across both the unilateral and bilateral groups. Only two out of 29 eyes (fewer than 10\%) were not enucleated. In a recent retrospective study of 18 group D eyes with bilateral disease that were treated with vincristine, etoposide and carboplatin, with a follow-up period of two years, two $(11 \%)$ responded to chemotherapy alone, nine $(50 \%)$ underwent successful salvage treatment including EBRT and seven (39\%) were enucleated. ${ }^{30}$ Considering that advanced disease is critical to eye preservation, we should mention the impressive results reported in a retrospective study of 63 eyes treated with primary EBRT - 93.6\% recovery in 5 years and $52.6 \%$ in 18.5 years. ${ }^{13}$

Despite the long lag time, the advanced stage of the tumor at diagnosis and one eye classified as Chantada II (residual microscopic tumor after enucleation), all children but one are still alive. The only fatal outcome was observed in the patient who presented with CNS invasion. The pathologic findings show that even though no significant difference was found between the two groups concerning 
pathological features, nerve invasion was slightly more frequent in unilateral tumors $(\mathrm{p}=0.056)$, with more than $40 \%$ showing post laminar disease. These results must be kept in mind when indicating conservative treatment for large unilateral tumors.

In summary, retinoblastoma is a rare neoplasm at our institution, occurring at a frequency of fewer than one new case per month. Unilateral disease presents at an older age than bilateral disease, 33 months versus 19 months, and for most patients the presenting symptom is leucocoria. We still record a critical rate of $100 \%$ enucleation for unilateral disease cases and cases of bilateral enucleation due to late diagnosis. For bilateral retinoblastoma, the initial two-drug regime in addition to early focal treatment allowed for 11 eyes $(42.4 \%)$ to be salvaged without radiotherapy, and two eyes $(7.6 \%)$ with radiotherapy.

\section{ACKNOWLEDGMENT}

The authors thank Creusa Maria Roveri Dal Bó for the Statistical Analysis.

\section{REFERENCES}

1. Knudson AG Jr. Mutation and cancer: statistical study of retinoblastoma. Proc Natl Acad Sci USA. 1971;68:820-3.

2. Murphree AL, Villablanca JG, Deegan WF 3rd, Sato JK, Malogolowkin M, Fisher A, et al. Chemotherapy plus local treatment in the management of intraocular retinoblastoma. Arch Ophthalmol. 1996;114:1348-56.

3. Shields C.L, Honavar SG, Meadows AT, Shields JA, Demirci H, Naduvilath TJ. Chemoreduction for unilateral retinoblastoma. Arch Ophthalmol. 2002;120:1653-58.

4. Lumbroso L, Doz F, Urbieta M, Levy C, Bours D, Asselain B, et al. Chemothermotherapy in the management of retinoblastoma. Ophthalmology. 2002;109:1130-6.

5. Erwenne CM, Antonelli CBG, Marback EF, Novaes PE. Tratamento conservador em retinoblastoma intraocular. Arq Bras Oftalmol. 2003;66:791-5.

6. Murphree AL, Samuel MA, Harbour JW, Mansfield NC. Retinoblastoma. In Ryan SJ, editor. Retina. $3^{\text {rd }}$ ed. St. Louis: C.V. Mosby Co; 2001. p. 582 .

7. Tolentino FI, Tablante RT: Cryotherapy of retinoblastoma. Arch Ophthalmol. 1972,87:52-5.

8. Wilson TW, Chan HSL, Moselhy GM, Heydt DD, Frey CM, Gallie BL. Penetration of chemotherapy into vitreous is increased by cryotherapy and cyclosporine in rabbits. Arch Ophthalmol. 1996;114:1390-5.

9. Shields CL, Shields JA, Cater J, Othmane I, Singh AD, Micaily B: Plaque radiotherapy for retinoblastoma: a long-term tumor control and treatment complications in 208 tumors. Ophthalmology. 2001;108:2116-21.

10. Ellsworth RM: The practical manegement of retinoblatoma. Trans Am Ophthalmol Soc. 1969;67:462-534.

11. Phillips C, Sexton M, Weeler G, McKenzie J. Retinoblatoma: review os 30 years'experience with external beam radiotherapy. Australas Radiol. 2003; 47:226-30

12. Abramson DH, Frank CM. Second nonocular tumors in survivors of bilateral retinoblastoma: a possible age effect on radiation-related risk. Ophthalmology. 1998;105:573-80.
13. Abramson DH, Beaverson KL, Chang ST, Dunkel IJ, McCormick B. Outcome following initial external beam radiotherapy in patient with Reese-Ellsworth group Vb retinoblastoma. Arch Ophthalmol. 2004:122:1316-23

14. Murphree AL, Samuel MA, Harbour JW, Mansfield NC: Retinoblatoma in Ryan SJ: Retina mosby-Year Book, Inc St. Louis, 3rd ed. 2006, p.568.

15. Wilson MW, Rodriguez-Galindo C, Haik BG, Moshfeghi DM, Merchant TE, Pratt CB. Multiagent chemotherapy as neoadjuvant treatment for multifocal intraocular retinoblastoma. Ophthalmology. 2001;108:210614 ; discussion 2114-5.

16. Shields CL, Mashayekhi A, Cater J, Shelil A, Meadows AT, Shields JA. Chemoreduction for retinoblastoma: analysis of tumor control and risks for recurrence in 457 tumors. Trans Am Ophthalmol Soc. 2004;102:3544; discussion 44-5.

17. Shields CL, Shields JA, Needle M, Potter PD, Kheterpal S, Hamada A, et al. Combined chemoreduction and adjuvant treatment for intraocular retinoblastoma. Ophthalmology. 1997; 104:2101-11.

18. Reese, AB, Ellsworth RM: The evaluation and current concep in retinoblastoma therapy. Trans Am Acad Ophthalmol Otolaryngol. 1963;67:164-72.

19. Murphree AL: Intraocular retinoblastoma: The Case for a New Group Classification. Ophthalmol Clin N Am. 2005;18:41-53.

20. Chantada G, Fandiño A, Casak S, Manzitti J, Raslawski E, Schartzman E. Treatment of overt extraocular retinoblastoma. Med Pediatr Oncol. 2003;40:158-61.

21. Antoneli CB, Ribeiro KC, Steinhorst F, Novaes PE, Chojniak MM, Malogolowkin M. Treatment of retinoblastoma patients with chemoreduction plus local therapy: experience of the AC Camargo Hospital, Brazil. J Pediatr Hematol Oncol. 2006;28:342-5.

22. Carvalho R de S, José NK. Ophthalmology emergency room at the University of São Paulo General Hospital: a tertiary hospital providing primary and secondary level care. Clinics. 2007;62:301-8. 
23. Broaddus E, Tophan A, Singh AD. Incidence of retinoblastoma in the United States: 1975-2004. Br J Ophthalmol. 2008; AUG 21. [Epub ahead of print] PMID: 18718969.

24. Antoneli CB, Steinhorst F, de Cássia Braga Ribeiro K, Novaes PE, Chojniak MM, Arias V, et al. Extraocular retinoblastoma: a13 year experience. Cancer. 2003;98:1292-8.

25. Orjuela MA, Titievsky L, Liu X, Ramirez-Ortiz M, Ponce-Castaneda V, Lecona $\mathrm{E}$, et al. Fruit and vegetable intake during pregnancy and risk for development of sporadic retinoblastoma. Cancer Epidemiol Biomarkers Prev. 2005;14:1433-40.

26. Orjuela M, Castaneda VP, Ridaura C, Lecona E, Leal C, Abramson DH, et al. Presence of human papilloma virus in tumor tissue from children with retinoblastoma: an alternative mechanism for tumor development. Clin Cancer Res. 2000;6:4010-6.

27. Palazzi MA, Yunes JA, Cardinalli IA, Stangenhaus GP, Brandalise SR, Ferreira SA, et al. Detection of oncogenic human papillomavirus in sporadic retinoblastoma. Acta Ophthalmol Scand. 2003;81:396-8
28. Abramson DF, Frank CM, Susman M, Whalen MP, Dunkel IJ, Boyd NW $3^{\text {rd }}$. Presenting signs of retinoblastoma. J Pediatr 1998;132:505-8.

29. Shields CL, Santos MC, Diniz W, Gunduz K, Mercado G, Cater JR, et al. Thermotherapy for retinoblastoma. Arch Ophthalmol. 1999;117:88593.

30. Cohen VW, Kingston JE, Hungerford JL. The success of primary chemotherapy for group D heritable retinoblatoma. Br. J Ophthalmol 2008 aug 2008, Epud ahead of print

31. Wilson MW, Haik BG, Liu T, Merchant TE, Rodriguez-Galindo C. Effect on ocular survival of adding early intensive focal treatments to a two-drug chemotherapy regimen in patients with retinoblastoma. Am J Ophthalmol. 2005;140:397-406.

32. Gündüz K, Günalp I, Yalçindag N, Ünal E, Taçyildiz N, Erden E, et al. Causes of chemoreduction failure in retinoblatoma and analysis of associated factors leading to eventual treatment with external beam radiotherapy and enucleation. Ophthalmology. 2004;111:1917-24. 